\title{
Insights into semen analysis: a Chinese perspective on the fifth edition of the WHO laboratory manual for the examination and processing of human semen
}

\author{
Wen-Hong Lu, Yi-Qun Gu \\ National Research Institute for Family Planning, Beijing 100081, China
}

Asian Journal of Andrology (2010) 12: 605-606. doi: 10.1038/aja.2010.36; published online 14 June 2010.

Correspondence to: Prof. Yi-Qun Gu, National Research Institute for Family Planning, Beijing 100081, China.

Fax: +86-10-6217-3451

E-mail: ygu90@yahoo.cn

Received: 23 March 2010

Revised: 28 April 2010

Accepted: 13 May 2010

Published online: 14 June 2010

Dear Editor,

We are very glad to see that the Asian Journal of Andrology published a Special Issue on Semen Analysis in 21 st Century Medicine, which well revealed some behind-the-scene controversies of the 5 th edition of the WHO laboratory manual for the examination and processing of human semen [1]. Three articles from the special issue, two on the reference values of semen parameters $[2,3]$ and another presenting the investigation results of 118 laboratories performing semen analysis in Mainland China [4], are very thoughtprovoking and we would like to share some of our views on these topics.

First, we noticed that the lower limit of the reference values of semen parameters in the 5 th edition of the manual is reduced. Can this reduction reflect a genuine decline in semen quality? We are doubtful on this point. The reasons for the reduction vary from the variations in population selection, and the biases in methodologies of measurement and data processing to the recommended application of 'stricter criteria'. It has been a long time since the change in semen quality of healthy men become a controversial issue throughout the world. There is no definite conclusion on the trend of overall semen quality, owing to the differences in study design, definition of normal men, specimen collection methods, methods used for measurement of sperm and for statistical analysis, selection biases, measurement errors, regional differences, and other factors such as age, years spent in semen collection, the period of abstinence, etc. In addition, researches on change of semen quality are only retrospective analyses. Various insurmountable biases and confounding factors also make the conclusion poorly reliable. Although careful efforts were made to reduce the biases in some studies, discrepancies in results still remained. With the publication of the 5th edition of the WHO manual, more concerns and debates would be aroused. So far, it is not yet known whether the reduced lower limit of the reference values can indicate the decline in semen quality, but strictly evidence-based study design, standardization of measurement criteria and quality control (QC) of semen analysis would explain the reduction in the lower limit.

Second, we think it is necessary to establish the reference intervals for values of semen parameters based on a fertile population using the time-to-pregnancy method in China. Semen quality is commonly taken as a surrogate indicator of male fertility, reproductive toxicology, epidemiology and pregnancy risk assessments. Reference intervals for values of semen parameters from a fertile population and the standardization of procedures for the examination of human semen given in the 5 th edition of the manual provide a realistic basis for medical professionals all over the world, especially in China, where more than one-fifth of the world population inhabits. China is in urgent need of reference values of semen 
parameters derived from fertile Chinese men, which calls for a prospective, multi-center and nation-wide population-based study. Such a large-scale study will provide evidence for the prognosis of fertility, diagnosis of infertility and impact of environmental factors on human existence. It will also be helpful for the State Food and Drug Administration of China to establish medical guidelines for male fertility regulation.

Third, internal and external QC of semen analysis need to be further improved. Semen analysis is used widely and has a significant role in the assessment of male fertility. There have been reports on the absence of standardization on semen analysis [5-8] and obvious differences among laboratories [9-11], and some researchers have called for a comprehensive QC [12-16]. The lack of consistency and standardization [17] incurs difficulties for clinicians to interpret or compare the results of semen analysis from different laboratories. Therefore, improvements in the following aspects would help improve the quality of semen analysis and ensuring the reliability of the results: using accredited and standard measurement, implementing internal QC and external QC.

Finally, the criterion for determining an eligible donor in China should be revised accordingly to elevate the present poor eligibility after comprehensive investigations. The current quality requirements for an eligible donor's semen as per the Essential Criterion and Technical Specification of the Human Sperm Bank, issued by the Ministry of Health of China, are based on the 4 th edition manual. With the reduction in certain semen parameters such as semen concentration, motility and semen volume in the 5th edition, we believe that studies on the reference intervals for values of semen parameters from fertile men must be carried out before any modification of the criteria is made in China. Such expanded studies would lead experts to conduct extensive discussions and would thus provide informative suggestions for policy makers before making any modification in the criteria of the human sperm bank in China.

\section{References}

1 World Health Organization. WHO Laboratory Manual for the Examination and Processing of Human Semen, 5th edn. Geneva: World Health Organization; 2010.

2 Boyd JC. Defining laboratory reference values and decision limits: populations, intervals, and interpretations. Asian J Androl 2010; 12: 83-90.

3 Skakkebaek NE. Normal reference ranges for semen quality and their relations to fecundity. Asian J Androl 2010; 12: 95-8.

4 Lu JC, Zhang HY, Hu YA, Huang YF, Lü NQ. A survey on the status of semen analysis in 118 laboratories in China. Asian J Androl 2010; 12: 104-10.

5 Chong AP, Walters CA, Weinrieb SA. The neglected laboratory test. The semen analysis. J Androl 1983; 4: 280-2.

6 Ombelet W, Pollet H, Bosmans E, Vereecken A. Results of a questionnaire on sperm morphology assessment. Hum Reprod 1997; 12: 1015-20.

7 Keel BA, Stembridge TW, Pineda G, Serafy NT Sr. Lack of standardization in performance of the semen analysis among laboratories in the United States. Fertil Steril 2002; 78: 603-8.

8 Keel BA. How reliable are results from the semen analysis? Fertil Steril 2004; 82: 41-4.

9 Ayodeji O, Baker HW. Is there a specific abnormality of sperm morphology in men with varicoceles? Fertil Steril 1986; 45: 839-42.

10 Neuwinger J, Bejre HM, Nieschlag E. External quality control in the andrology laboratory: an experimental multicenter trial. Fertil Steril 1990; 54: 308-14.

11 Keel BA, Quinn P, Schmidt CF Jr, Serafy NT Jr, Serafy NT Sr, et al. Results of the American Association of Bioanalysts national proficiency testing programme in andrology. Hum Reprod 2000; 15: 680-6.

12 Cooper TG, Neuwinger J, Bahrs S, Nieschlag E. Internal quality control of semen analysis. Fertil Steril 1992; 58: 172-8.

13 Mortimer D. Practical Laboratory Andrology. New York: Oxford University Press; 1994.

14 Clements GN, Cooper TG, Barratt CL. Implementing comprehensive quality control in the andrology laboratory. Hum Reprod 1995; 10: 2096-106.

15 Cooper TG, Atkinson AD, Nieschlag E. Experience with external quality control in spermatology. Hum Reprod 1999; 14: 765-9.

16 Keel BA. Quality control, quality assurance, and proficiency testing in the andrology laboratory. Arch Androl 2002; 48: 417-31.

17 Keel BA. How reliable are results from the semen analysis? Fertil Steril 2004; 82: 41-4. 